\title{
LINEAMENTOS DE DRENAGEM EM SETOR DE TRANSIÇÃO CUESTAS-DEPRESSÃO PERIFÉRICA: CONTRIBUIÇÃO À ANÁLISE MORFOESTRUTURAL DA REGIÃO DE ANALÂNDIA (SP)
}

\author{
Leandro de Godoi Pinton ${ }^{(a)}$, Cenira Maria Lupinacci ${ }^{(b)}$ \\ (a) Instituto Federal de Educação, Ciência e Tecnologia de São Paulo (IFSP), Câmpus São Carlos (SP). E-mail: \\ lgpgeo@yahoo.com.br \\ (b) Departamento de Planejamento Territorial e Geoprocessamento/Instituto de Geociências e Ciências Exatas, \\ Universidade Estadual Paulista (UNESP), Câmpus Rio Claro (SP). E-mail: cenira @ rc.unesp.br
}

\section{Eixo: SISTEMAS GEOMORFOLÓGICOS: ESTRUTURA, DINÂMICAS E PROCESSOS}

\begin{abstract}
Resumo
O presente artigo teve como objetivo apresentar os resultados obtidos no mapeamento dos lineamentos da rede de drenagem em setor transicional Cuestas-Depressão Periférica Paulista. Com base nessa apresentação, discutir algumas implicações do controle estrutural no desenvolvimento de processos morfogenéticos e de feições morfotectônicas do relevo cuestiforme. Os lineamentos foram extraídos com base na interpretação visual de trechos retilíneos e formas anômalas dos cursos d'água circunscritos em recorte da carta topográfica Corumbataí (SF-23-Y-A-I-2), na escala 1:50.000. A disposição direcional dos lineamentos de drenagem mapeados demonstra uma configuração polimodal, sendo as famílias N-S, E-W, NE-SW e NW-SE preponderantes na área de estudo. No âmbito do relevo cuestiforme, essas direções possuem correspondência com os sistemas de descontinuidades estruturais associados às deformações neotectônicas regionais. Desta forma, admitese que as linhas de fraqueza instituídas por esse arranjo morfoestrutural influenciam na evolução recente de processos morfogenéticos e de feições morfotectônicas do relevo de cuestas.
\end{abstract}

Palavras-chave: Geomorfologia do Quaternário. Bacia Sedimentar do Paraná. Morfotectônica.

\begin{abstract}
This study aimed to present the results obtained by mapping the drainage network lineaments in a transitional sector of the Cuestas-Paulista Peripheral Depression. Implications of structural control on development of morphogenetic processes and morphotectonic features of the cuesta relief were discussed based on this presentation. The lineaments were extracted by visual interpretation of rectilinear segments and anomalous forms from watercourses circumscribed in a clipping of Corumbataí topographic map (SF-23-Y-A-I-2), on scale of 1: 50,000. The directional arrangement of the drainage lineaments demonstrated a poliymodal configuration. The predominant families in the study area are: N-S, E-W, NE-SW and NW-SE. The cuesta relief was characterized by the same trends, which are related to the structural discontinuities systems associated with regional neotectonic deformations. The lines of weakness established by these morphostructural arrangement influence the recent evolution of cuesta relief morphogenetic processes and morphotectonic features.
\end{abstract}

Keywords: Quaternary Geomorphology. Paraná Sedimentary basin. Morphotectonics. 


\section{Introdução}

A análise morfoestrutural se constitui como instrumento de investigação do papel exercido pelas condições litoestruturais na evolução do relevo e da paisagem em seu conjunto.

Essa abordagem foi preconizada inicialmente nos estudos de geomorfólogos da escola soviética, tais como aqueles realizados por Gerasimov (1946), Gerasimov e Mescerjakov (1967), Mescerjakov (1968) e Demek (1972).

Em consonância com os princípios básicos desses autores, Corrêa et al. (2010, p. 37) definem a morfoestrutura como sendo um arranjo hierárquico de feições, que engloba "desde conjuntos regionais de primeira ordem de grandeza (megamorfoestruturas) até as menores ordens (micromorfoestruturas), tais como os grábens e cimeiras em cristas de expressão local”.

A amplitude escalar dessa concepção respalda a diversidade de aplicações da análise morfoestrutural nas investigações geomorfológicas de questões teóricas e aplicadas. Em ambas as situações, verifica-se a utilização de informações sobre a presença e características dos lineamentos para o entendimento da configuração morfoestrutural da paisagem, tendo em vista que esses expressam a influência de descontinuidades estruturais.

No âmbito das pesquisas aplicadas, os dados acerca dessas feições têm auxiliado no desenvolvimento de distintas atividades antrópicas, como obras de engenharia (MOURA; RUEDA; MATTOS, 2009); prospecção de minerais (RICCOMINI; CRÓSTA, 1988; TAYLOR, 1988; MATTOS et al., 1982; SOARES et al., 1982) e; planejamento urbano e rural (JIMÉNEZ-RUEDA; NUNES; MATTOS, 1993).

No que tange às discussões teóricas, os lineamentos têm fornecido subsídios para a interpretação de processos morfogenéticos nas mais variadas paisagens, sendo ainda incorporados na fundamentação de estudos sobre a incidência de deformações neotectônicas em diversos contextos geoestruturais (SAADI, 1993; CENTAMORE et al., 1996; ETCHEBEHERE; SAAD; CASADO, 2005; FACINCANI, 1995, 2000; ANDRADES-FILHO; GUASSELLI; SUERTEGARAY, 2007; DEMEK et al., 2007; CORRÊA et al., 2010; GUEDES, 2014; BARCELONA et al., 2014; GUEDES et al., 2015; ESPINOZA et al. 2015; LOPES et al., 2016; PINTON, 2016).

Amplamente consolidada na literatura geomorfológica como elemento indicador de atividades tectônicas, as anomalias de drenagem foram priorizadas na sistematização desses estudos. Nessa perspectiva, destacase a hegemônica extração dos lineamentos mediante investigação da rede de drenagem.

Diante dessas premissas, e da complexidade dos mecanismos morfogenéticos que envolvem a transição entre as Cuestas Areníticas-Basálticas e a Depressão Periférica Paulista (AB’SÁBER, 1949; PENTEADO, 1968; FACINCANI, 2000; PINTON, 2016), torna-se necessário analisar o arranjo de seus lineamentos de 


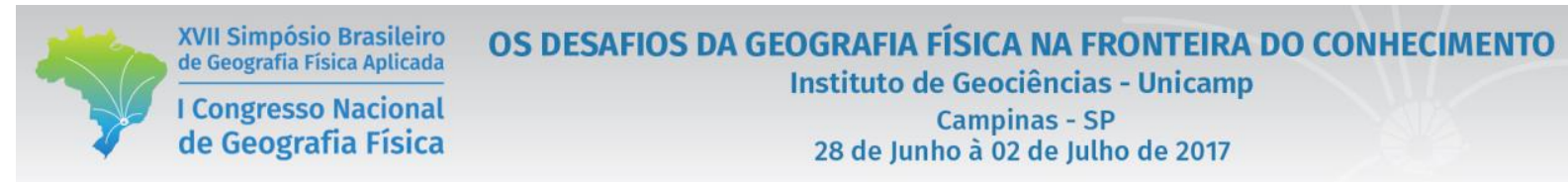

drenagem para contribuir na identificação das zonas de fraqueza que condicionam a evolução dessa paisagem.

Assim, este artigo teve como objetivo apresentar os resultados obtidos no mapeamento dos lineamentos da rede de drenagem em setor transicional Cuestas-Depressão Periférica Paulista. Com base nessa apresentação, discutir algumas implicações do controle estrutural no desenvolvimento de processos morfogenéticos e de feições morfotectônicas do relevo cuestiforme.

\section{2. Área de estudo}

O setor selecionado para o presente estudo compreende um recorte da carta topográfica Corumbataí (Folha SF-23-Y-A-I-2) na escala 1:50.000 do IBGE (1971). Esse recorte está localizado na porção centroleste do Estado de São Paulo, entre as coordenadas geográficas de $22^{\circ} 04^{\prime} 21^{\prime \prime}$ e $22^{\circ} 12^{\prime} 12^{\prime \prime}$ de latitude Sul e 47030'50' e 4744'24'" de longitude Oeste, possuindo uma área de 346,2 km² (Figura 1), que engloba predominantemente o município de Analândia e uma pequena parcela de Corumbataí.

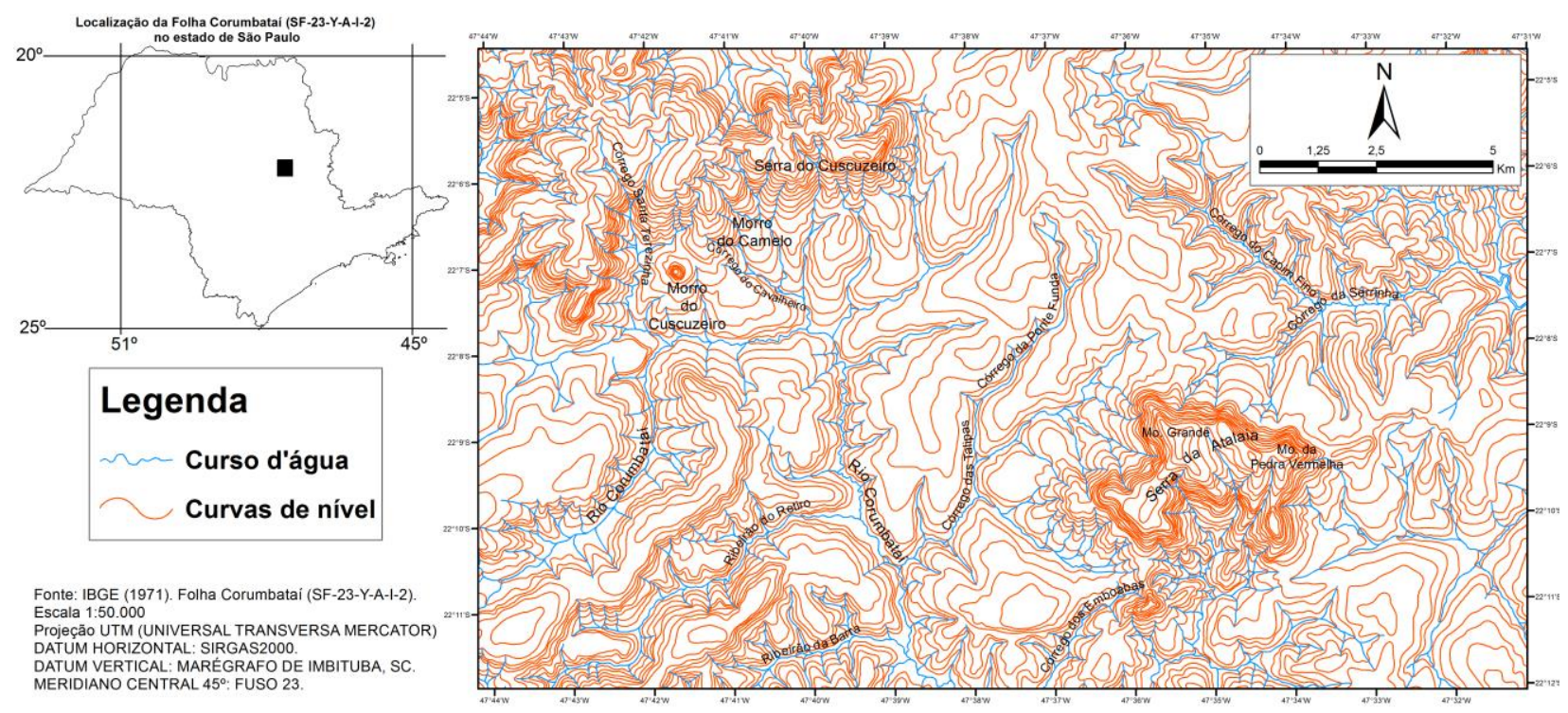

Figura 1 - Localização da área de estudo.

A área de estudo situa-se na Bacia Sedimentar do Paraná, unidade geotectônica de abrangência mercosulina preenchida por sedimentos continentais e marinhos, e extensa cobertura de rochas basálticas (ALMEIDA et al., 1981). 
De acordo com a proposição de Ross e Moroz (1997) para a representação do relevo paulista, a área de estudo está disposta no limite entre o Planalto Residual de São Carlos e a Depressão do Médio Tietê, sendo esse contato marcado pela eminente presença de escarpas cuestiformes.

Nesse setor transicional, o Planalto Residual de São Carlos é caracterizado por formas de dissecação média, com vales entalhados e densidade de drenagem média a alta, implicando numa fragilidade potencial média a muito alta.

A Depressão do Médio Tietê, por sua vez, apresenta o mesmo comportamento relatado aos índices das formas de dissecação, vales e densidade de drenagem da unidade supracitada. Nessa região depressionária, tal disposição define um nível de fragilidade potencial médio a baixo. Apesar disso, Ross e Moroz (1997) atentam para a existência de áreas susceptíveis ao desenvolvimento de processos erosivos com maior intensidade nessa unidade, as quais estão associadas aos terrenos constituídos por arenitos das formações Botucatu e Pirambóia.

As referidas características da rede de drenagem desses compartimentos podem estar associadas às linhas de fraqueza instituídas por fraturas e falhas. Alguns estudos (PENTEADO, 1968; FACINCANI, 2000; PINTON, 2016) admitem a influência de tais linhas no desenvolvimento dos processos denudativos responsáveis pela gênese e evolução de ambos os compartimentos e, consequentemente do relevo cuestiforme. Esses pressupostos incorporam a tectônica na clássica perspectiva de Ab'Sáber (1949) sobre a dinâmica da circundenudação, suscitando ao caráter complexo dos mecanismos morfogenéticos que abarcam tais unidades geomorfológicas. Desta forma, essa conjuntura corrobora a necessidade da proposição do presente artigo.

\section{Metodologia}

A conformação estrutural da área de estudo foi inferida com base na análise de seus lineamentos de drenagem. Ressalta-se o entendimento dos lineamentos conforme definição de Sabins Jr. (1978), que compreende esses como sendo feições lineares topográficas ou tonais no terreno ou em imagens e mapas, podendo representar zonas de fraqueza estrutural.

Os lineamentos de drenagem distinguem-se como aqueles formados em quebra negativa, expressos predominantemente na disposição em linha reta dos cursos d'água (SOARES; FIORI, 1976).

Neste estudo, optou-se pela identificação desse tipo de lineamento em função do preceito da rede de drenagem se constituir como elemento da paisagem que se ajusta de forma imediata às atividades tectônicas. Dessa forma, a sua análise pode auxiliar no fornecimento de informações sobre a configuração de descontinuidades estruturais no setor transicional Cuestas-Depressão Periférica Paulista. 


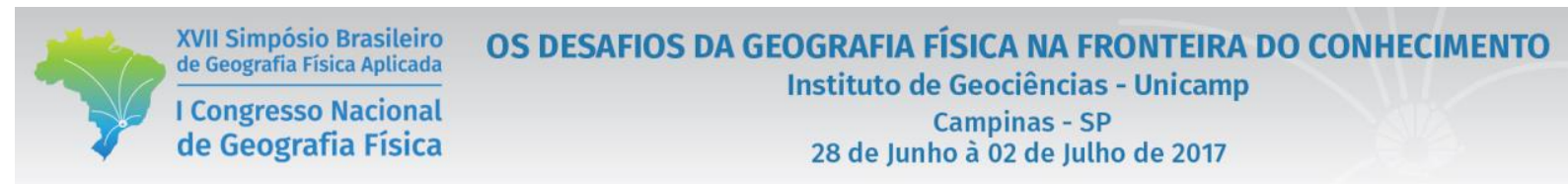

A extração dos lineamentos de drenagem foi realizada no ambiente do software ArcGIS Desktop 10.2.2 com base na vetorização por interpretação visual de trechos retilíneos e formas anômalas (cotovelos) dos cursos d'água circunscritos no recorte da carta topográfica Corumbataí (Folha SF-23-Y-A-I-2).

Para caracterizar a disposição direcional dos lineamentos de drenagem da área de estudo, foram elaboradas rosetas de frequência com o intervalo angular de $22,5^{\circ}$.

\section{Resultados}

No total, foram extraídos 553 lineamentos de drenagem (Figura 2). De acordo com a análise do diagrama de rosetas da área de estudo (Figura 2C), verificou-se a maior expressividade da família de lineamentos NS, e a existência marcante de outras três: E-W, NE-SW e NW-SE.

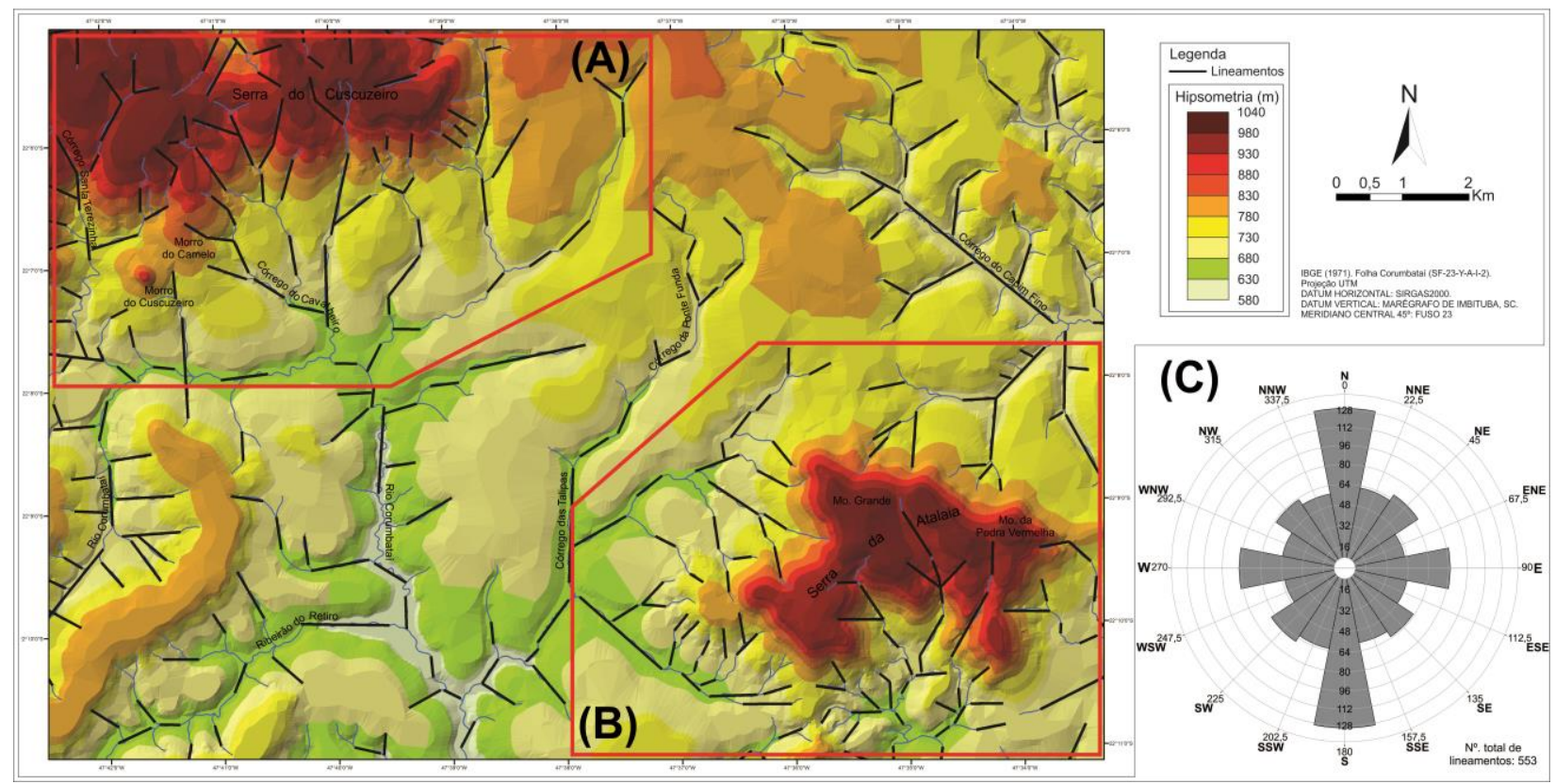

Figura 2 - Mapa de lineamentos da rede de drenagem e hipsometria da área de estudo. A e B. Setores de análise do relevo cuestiforme; C. Diagrama de roseta dos lineamentos de drenagem da área de estudo.

Ao considerar a distribuição espacial dos lineamentos de drenagem (Figura 2), admite-se a maior concentração desses nos setores localizados no noroeste (Figura 2A) e sudeste (Figura 2B) da área de estudo. Esses setores compreendem, respectivamente, um trecho do front cuestiforme da Serra do Cuscuzeiro e extenso testemunho derivado de seu recuo, denominado regionalmente e nos documentos cartográficos oficiais (IBGE, 1971) de Serra da Atalaia. 


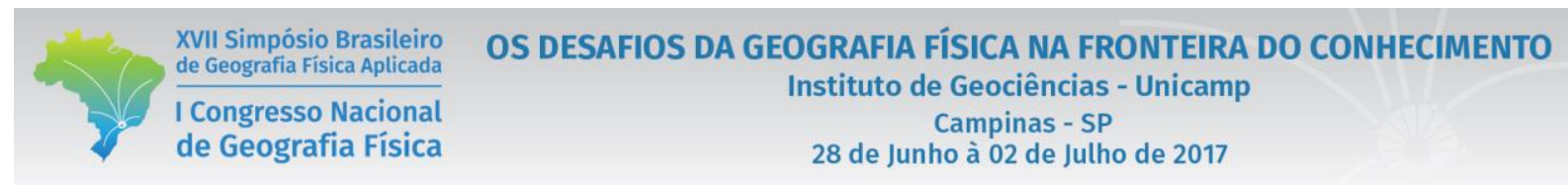

As informações de hipsometria, inseridas no mapa de lineamentos da rede drenagem da área de estudo (Figura 2), possibilitam o delineamento dessas feições, sendo essas distinguidas nos trechos dos setores quantificados com faixas de altitude entre 780 a 1040 metros.

Com o intuito de identificar os pormenores dos lineamentos de drenagem da paisagem do relevo cuestiforme, realizou-se uma caracterização de seu arranjo nos referidos setores. Neste viés, foram identificados os seguintes aspectos:

a) Setor Serra do Cuscuzeiro (Figura 3): composto por 122 lineamentos; predomínio das famílias de lineamentos N-S, NNE-SSW e E-W, e de forma secundária, daquelas com direção NW-SE e WNWESSE;

b) Setor Serra da Atalaia (Figura 4): totaliza 117 lineamentos; maior quantidade de lineamentos com direção N-S, e secundariamente das famílias NE-SW, E-W e NW-SE.

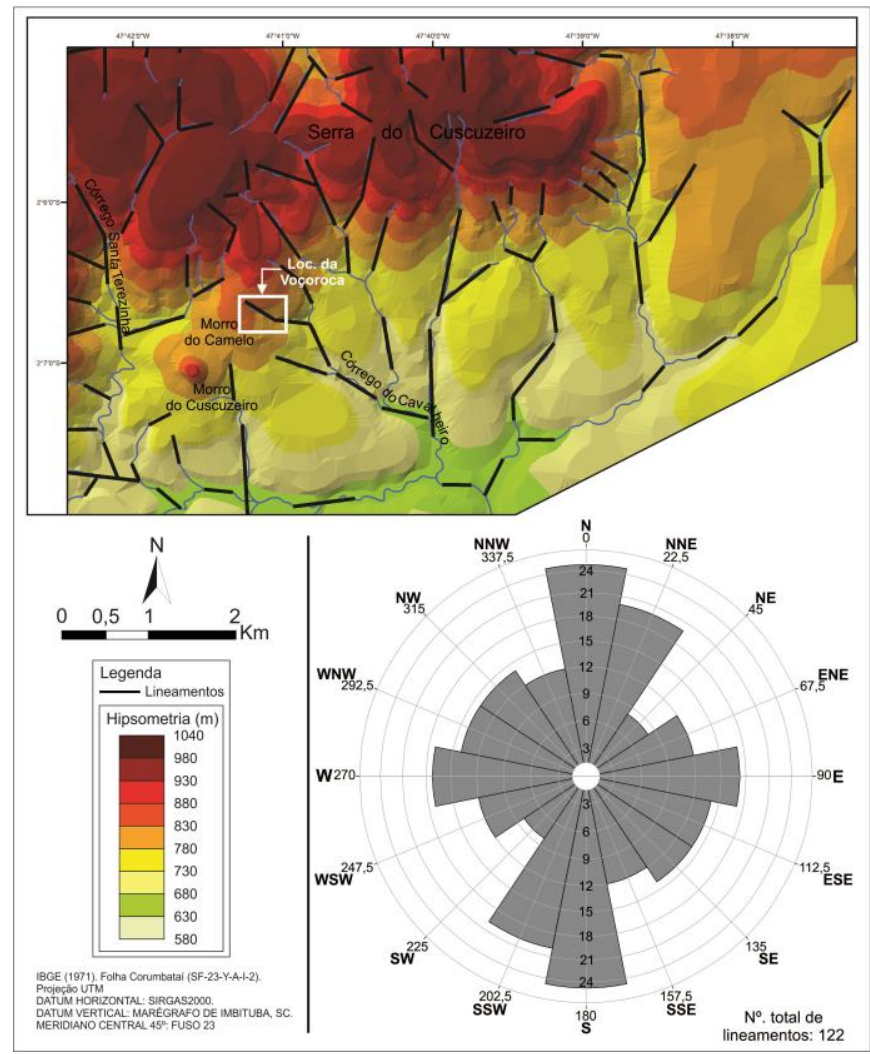

Figura 3 - Setor Serra do Cuscuzeiro e diagrama de roseta dos seus lineamentos de drenagem.

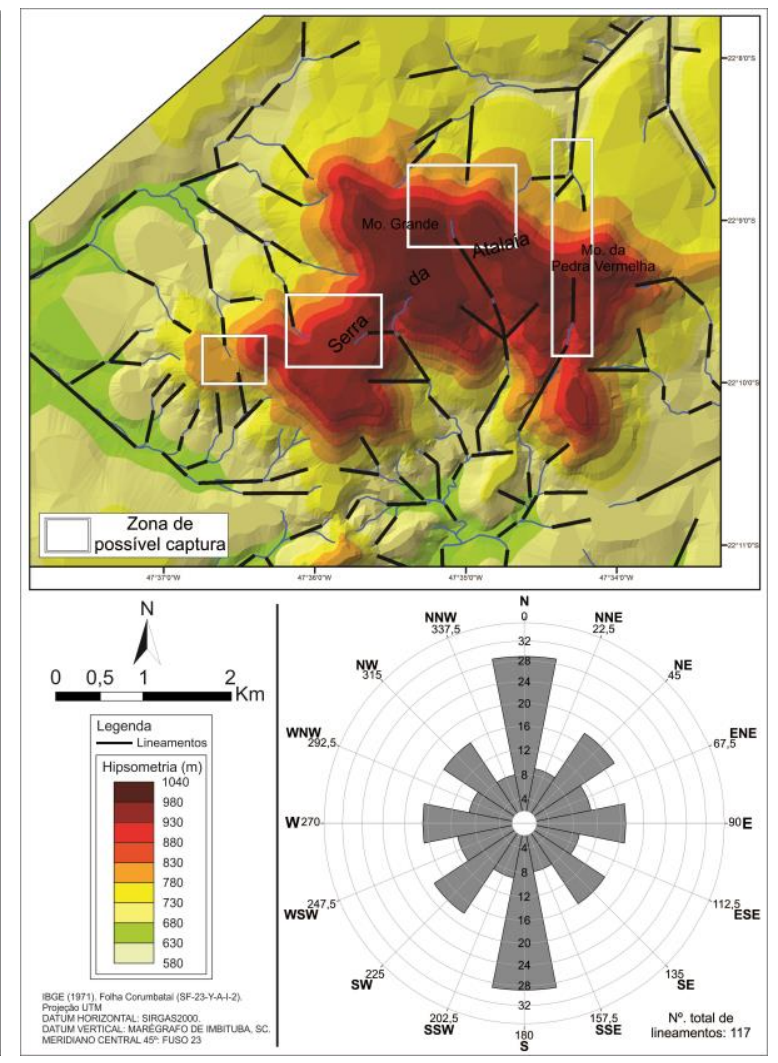

Figura 4 - Setor Serra da Atalaia e diagrama de roseta dos seus lineamentos de drenagem. 
XVII Simpósio Brasileiro de Geografia Física Aplicada

I Congresso Nacional de Geografia Física
OS DESAFIOS DA GEOGRAFIA FÍSICA NA FRONTEIRA DO CONHECIMENTO

Instituto de Geociências - Unicamp

Campinas - SP

28 de Junho à 02 de Julho de 2017

\section{Discussão}

A disposição direcional dos lineamentos de drenagem mapeados demonstra uma configuração polimodal. Apesar da existência de pequenas variações angulares nos setores individualizados que abarcam o relevo cuestiforme, constatou-se uma relativa similaridade nas direções de seus lineamentos com o quadro geral da área de estudo.

Essas direções possuem correspondência com os sistemas de descontinuidades estruturais identificados por Facincani (1995, 2000) e Silva (1997) em âmbito regional. Nesses estudos, alguns dos referidos sistemas foram colocados como sendo provenientes de um regime neotectônico. Nessa perspectiva, acredita-se que os lineamentos de drenagem da área de estudo podem estar associados às deformações neotectônicas regionais.

De acordo com as propostas de Facincani (2000) e Silva (1997), as zonas de fraqueza estabelecidas pelo conjunto de descontinuidades com direção NW-SE, NE-SW e N-S favoreceram o desenvolvimento de processos morfogenéticos e de feições morfotectônicas. Tal premissa também foi verificada na paisagem do relevo cuestiforme da área de estudo.

No setor Serra do Cuscuzeiro (Figura 3), a voçoroca de grande dimensão no tálus do morro testemunho do Camelo (Figura 5A), composta por inúmeros canais de $1^{\text {a }}$ ordem com orientação NW-SE (Figura 5B), denota controle estrutural. $\mathrm{O}$ direcionamento preferencial desses canais responde às zonas de fraqueza que influenciam na dissecação da escarpa de cuestas a NW (Figura 5A). Ressalta-se que a configuração dos referidos canais coincide com a direção das juntas e falhas verificadas por Facincani $(1995,2000)$ nos locais onde ocorrem voçorocas.

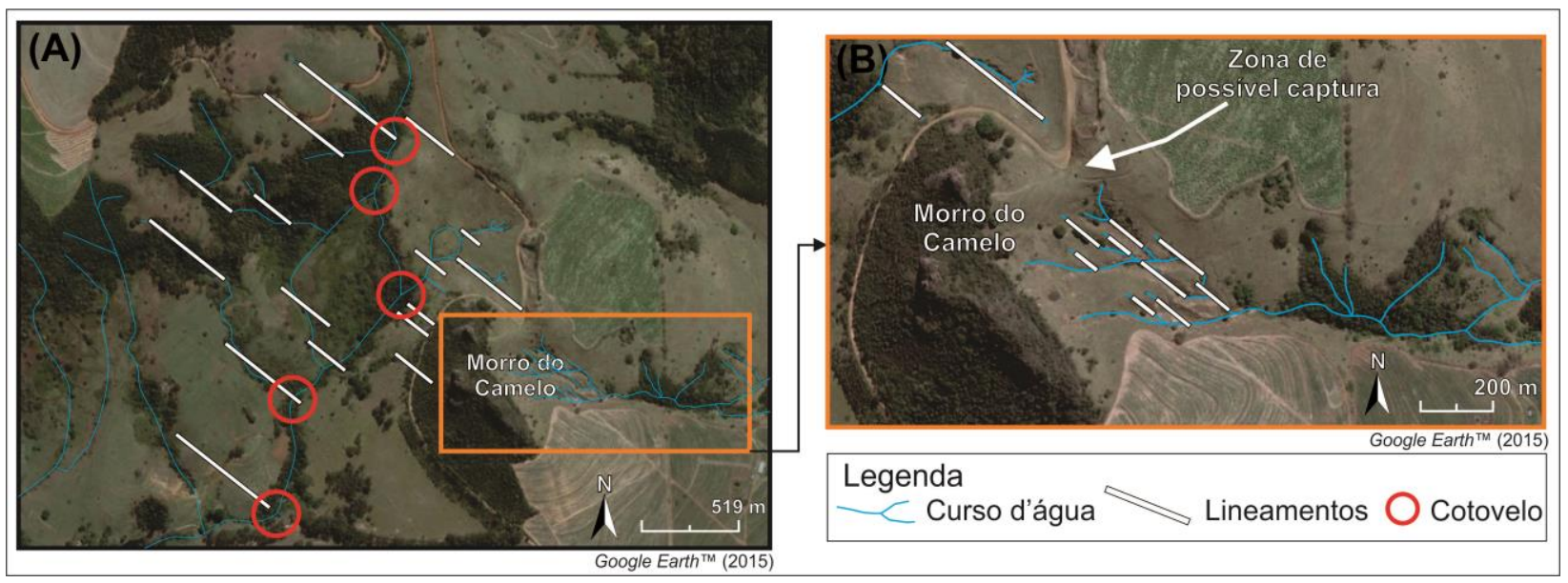

Figura 5 - Feições morfotectônicas no entorno do morro testemunho do Camelo. A. Voçoroca, cotovelos e sistema de fraturas NW-SE do escarpamento cuestiforme a NW do morro testemunho; B. Arranjo estrutural NW-SE dos canais de $1^{\mathrm{a}}$ ordem da voçoroca no setor de tálus do morro testemunho do Camelo e possível zona de captura. 


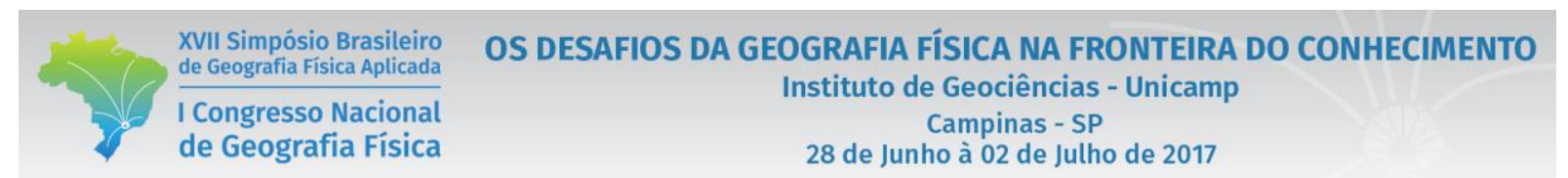

Essa conjuntura indica a aparente influência do fator tectônico na intensificação de processos erosivos. Ao lado disso, deve-se ponderar sobre a fragilidade desse setor, inerente de sua morfometria e composição litopedológica (CUNHA; PINTON, 2013), e às mudanças do uso da terra em área rural (PINTON; CUNHA, 2015).

A orientação preferencial NW-SE do Córrego do Cavalheiro (Figura 3) demonstra o seu condicionamento às zonas de fraqueza impostas por fraturas e falhas. O direcionamento NE-SW do curso d'água que drena a vertente oposta do morro testemunho do Camelo, equivalente ao afluente da margem esquerda do Córrego Santa Terezinha (Figura 3), também sugere o controle tectônico.

Facincani (2000) destaca que as mudanças de direção dos cursos d'água revelam feições morfotectônicas nas adjacências de Analândia, as quais fornecem evidências dos fenômenos de capturas influenciados pela neotectônica.

As possíveis retomadas erosivas, tanto do afluente da margem esquerda do Córrego Santa Terezinha, quanto do Córrego do Cavalheiro, podem levar a ocorrência de uma captura, contribuindo com a evolução do morro testemunho (Figura 5B).

A configuração dos cursos d'água na área que engloba os morros testemunhos do Camelo e do Cuscuzeiro (Figura 6) também evidencia o controle por estruturas de direção NW-SE e NE-SW. Ademais, verificouse a presença de lineamento de drenagem organizado no sentido N-S. Aparentemente, o cruzamento desses feixes de lineamentos acompanha as zonas de ruptura dos referidos morros testemunhos.

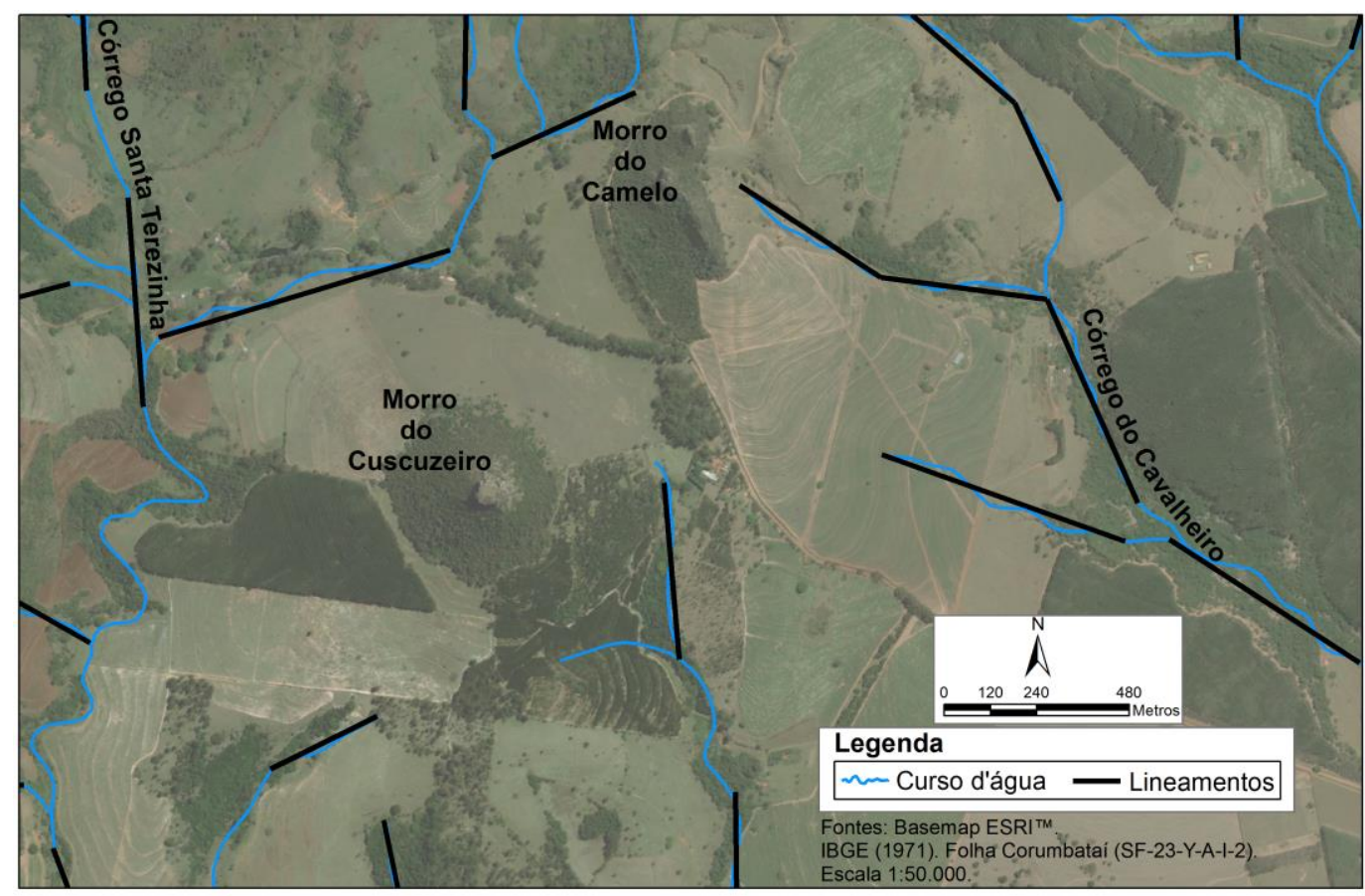

Figura 6 - Lineamentos de drenagem no entorno dos morros testemunhos do Camelo e do Cuscuzeiro. 
Cunha (2014) havia ponderado sobre a disposição espacial dessa rede de drenagem se constituir como indicativo da influência de estruturas falhadas no processo de esculturação e separação desses morros testemunhos do front cuestiforme.

No contexto regional, Penteado (1968) atribuiu às linhas tectônicas preexistentes ou reativadas, retratadas sob o mesmo conjunto de direções dos lineamentos de drenagem, a responsabilidade pelo seccionamento de morros testemunhos do conjunto de escarpas cuestiformes. Nessa mesma perspectiva, Facincani (2000) reforça o controle exercido por falhamentos modernos na dissecação das zonas de escarpas e consequente compartimentação de morros testemunhos.

No setor Serra da Atalaia (Figura 4), a análise do arranjo direcional de seus lineamentos de drenagem evidencia possíveis capturas. A evolução desse fenômeno configura zonas de cut-off do testemunho, expostas no seu seccionamento em dois proeminentes residuais - Morro Grande e Morro da Pedra Vermelha, e outros dois incipientes oriundos da dissecação de esporão localizado no extremo oeste.

Ao considerar que os cursos d'água envolvidos nessa conjuntura (Figura 4) estão ajustados às famílias de lineamentos predominantes do setor, acredita-se que a morfogênese desses residuais tem sido influenciada por estruturas de direção N-S, NE-SW, E-W e NW-SE. É importante salientar que essas linhas de fraqueza envolvem o sistema de falhamentos modernos distinguido por Facincani (2000) na evolução da Serra da Atalaia. A autora ainda destaca que as deformações de superfície derivadas desse quadro de descontinuidades afetam a atividade geomórfica responsável pela formação de depósitos neocenozóicos.

Pinton (2016) reafirma tal pressuposto ao reconhecer a influência de fragilidades estruturais na organização de depósitos coluvionares distribuídos nas margens das escarpas cuestiformes dos setores de análise do presente estudo. De acordo com o modelo evolutivo proposto por Pinton (2016) ao relevo cuestiforme no Quaternário Tardio, os mecanismos morfogenéticos que promoveram a deposição de material coluvionar na fase úmida do Holoceno Médio-Superior (de $7.420 \pm 980$ a $4.500 \pm 750$ anos A.P. conforme datação realizada pelo autor por Luminescência Opticamente Estimulada - LOE) podem ter sido induzidos pelas fragilidades provenientes da disposição da morfoestrutura local.

\section{Considerações finais}

O mapeamento dos lineamentos da rede de drenagem em setor transicional Cuestas-Depressão Periférica Paulista permitiu a identificação de descontinuidades que condicionam a organização de sua paisagem atual.

No âmbito do relevo cuestiforme, o predomínio das famílias de lineamentos N-S, E-W, NE-SW e NW-SE converge para o quadro neotectônico regional. Desta forma, admite-se que as linhas de fraqueza 


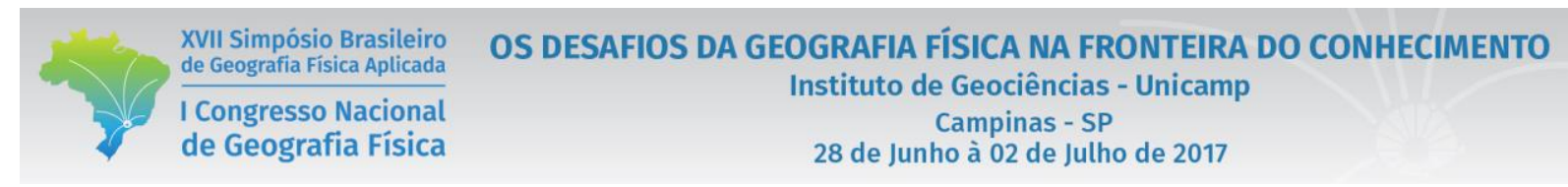

instituídas por esse arranjo morfoestrutural influenciam na evolução recente de processos morfogenéticos e de feições morfotectônicas do relevo de cuestas.

Tal conjectura foi corroborada mediante o reconhecimento do controle tectônico em cursos d'água responsáveis pelo desenvolvimento de voçorocas; zonas de possíveis capturas; dissecação das escarpas e subsequente cut-off do front cuestiforme, propiciando a formação de morros testemunhos e depósitos coluvionares.

Para o delineamento mais preciso do quadro de deformações neotectônicas do relevo cuestiforme da área de estudo, surge a necessidade de aprofundar a análise morfoestrutural empreendida no presente artigo por meio da investigação de outras variáveis que revelem atividades neotectônicas, tais como as anomalias fluviomorfométricas e os registros paleossísmicos.

Por fim, considera-se que os elementos estruturais sistematizados no arranjo dos lineamentos de drenagem da área de estudo incitam a complexidade da dinâmica evolutiva das cuestas da Bacia Sedimentar do Paraná ao longo do Quaternário.

\section{Agradecimentos}

À Fundação de Amparo à Pesquisa do Estado de São Paulo (FAPESP) pelo apoio ao desenvolvimento da pesquisa (Processo $n^{\circ}$ 2012/20513-0).

\section{Referências}

AB'SÁBER, A. N. Regiões de Circundesnudação pós-cretácea, no Planalto Brasileiro. Boletim Paulista de Geografia, São Paulo, n. 1, p. 3-21, mar. 1949.

ALMEIDA, F. F. M. de. et al. Brazilian structural provinces: an introduction. Earth-Science Reviews, v. 17, p. 1-29, 1981.

ANDRADES-FILHO, C. de O.; GUASSELLI, L. A.; SUERTEGARAY, D. M. Investigação sobre a relação entre lineamentos estruturais e a ocorrência de areais no sudoeste do Rio Grande do Sul. In: SIMPÓSIO BRASILEIRO DE GEOGRAFIA FÍSICA APLICADA, 12., 2007, Natal. Anais... Natal: Universidade Federal do Rio Grande do Norte, 2007. p. 243-257.

BARCELONA, H. et al. Tectonic activity revealed by morphostructural analysis: Development of the Sierra de la Candelaria range, northwestern Argentina. Journal of South American Earth Sciences, v. 56, p. 376-395, 2014.

CENTAMORE, E. et al. Morphological and morphometric approach to the study of the structural arrangement of northeastern Abruzzo (central Italy). Geomorphology, v. 16, p. 127-137, 1996.

CORRÊA, A. C. de B. et al. Megageomorfologia e morfoestrutura do Planalto da Borborema. Revista do Instituto Geológico, São Paulo, v. 31, n. 1-2, p. 35-52, 2010. 
CUNHA, C. M. L. da. A influência da morfoestrutura na disposição de morros testemunhos: o caso do setor de cuestas de Analândia (SP). Revista Geonorte, Manaus, Edição Especial 4, v. 10, n. 6, p. 105-110, 2014.

CUNHA, C. M. da; PINTON, L. de G. A cartografia do relevo como subsídio para a análise morfogenética de setor cuestiforme. Mercator, Fortaleza, v. 12, n. 27, p. 149- 158, jan./abr. 2013.

DEMEK, J. Manual of detailed geomorphological mapping. Praga: Academia-IGU, 1972.

DEMEK, J. et al. The map of morphostructures of the Czech Republic. Geomorphologia Slovaca et Bohemica, v. 1, p. 5-14, 2007.

ESPINOZA, G. de los Á. V. et al. La zonificación morfotectónica-volcánica en el análisis morfoestructural del relieve: el caso del municipio de Managua, Nicaragua. Investigaciones Geográficas, n. 87, p. 118-140, 2015.

ETCHEBEHERE, M. L. de C.; SAAD, A. R.; CASADO, F. da C. Análise morfoestrutural aplicada no vale do Rio do Peixe (SP): uma contribuição ao estudo da neotectônica e da morfogênese do Planalto Ocidental Paulista. Geociências - UNG, Guarulhos, v. 10, n. 6, p. 45-62, dez. 2005.

FACINCANI, E. M. Influência da estrutura e tectônica no desenvolvimento das boçorocas da região de São Pedro, SP: proposta de reabilitação e aspectos jurídico-institucionais correlatos. 1995. 124 f. Dissertação (Mestrado em Geociências e Meio Ambiente) - Instituto de Geociências e Ciências Exatas, Universidade Estadual Paulista, Rio Claro, 1995.

Morfotectônica da depressão periférica paulista e cuesta basáltica: regiões de São Carlos, Rio Claro e Piracicaba, SP. 2000. 222 f. Tese (Doutorado em Geologia Regional) - Instituto de Geociências e Ciências Exatas, Universidade Estadual Paulista, Rio Claro, 2000.

GERASIMOV, I. P. Experience with geomorphological interpretation of the general scheme of geological structure of URSS. Problemy fizicheskoy geografii, Moscou, v. 12, p. 89-115, 1946.

GERASIMOV, I. P.; MESCERJAKOV, J. A. Reljef Zemli (morfostruktura i morfoskulptura). Moscou: Nauka, 1967.

GUEDES, I. C. et al. Indicações de deformações neotectônicas na bacia do Rio Pardo-SP através de análises de parâmetros fluviomorfométricos e de imagens SRTM. Geociências, Rio Claro, v. 34, n. 3, p. 364-380, 2015.

GUEDES, I. C. Análise morfotectônica do Planalto Ocidental Paulista, ao sul do Rio Tietê: indicadores de deformações neotectônicas na fisiografia da paisagem. 2014. 2 v. Tese (Doutorado em Geologia Regional) - Instituto de Geociências e Ciências Exatas, Universidade Estadual Paulista, Rio Claro, 2014.

INSTITUTO BRASILEIRO DE GEOGRAFIA E ESTATÍSTICA - IBGE. Carta Topográfica Corumbataí (Folha SF-23-Y-A-I-2). Rio de Janeiro: IBGE, 1971. Escala 1:50.000.

JIMÉNEZ-RUEDA, J. R.; NUNES, E.; MATTOS, J. T. Caracterização fisiográfica e morfoestrutural da Folha São José de Mipibu, RN. Geociências, São Paulo, v. 12, n. 2, p. 481-491, 1993.

LOPES, F. C. et al. Morphostructural characterization of the western edge of the Huila Plateau (SW Angola), based on remote sensing techniques. Journal of African Earth Sciences, v. 117, p. 114-123, 2016.

MATTOS, J. T. et al. Análise morfoestrutural com uso de imagens MSS-Landsat e radar para pesquisa de hidrocarbonetos no estado de São Paulo. São José dos Campos: INPE, 1982. (Relatório do INPE-1445-RTR/015).

MESCERJAKOV, J. P. Les concepts de morphostructure et de morphosculture: um nouvel instrument de l'analyse geomorphologique. Annales de géographie, Paris, v. 77, n. 423, p. 538-552, 1968. 
MOURA, C. A. de; RUEDA, J. R. J.; MATTOS, J. T. de. Determinação de áreas instáveis em faixa de dutos utilizando imagens de satélite Landsat. In: SIMPÓSIO BRASILEIRO DE SENSORIAMENTO REMOTO, 14., 2009, Natal. Anais... Natal: INPE, 2009. p. 3277-3284.

PENTEADO, M. M. Geomorfologia do setor centro-ocidental da Depressão Periférica Paulista. 1968.86 f. Tese (Doutorado em Geografia Física) - Faculdade de Filosofia, Ciências e Letras de Rio Claro, Rio Claro, 1968.

PINTON, L. de G. Evolução dos processos morfogenéticos em relevo cuestiforme: a bacia do Córrego do Cavalheiro - Analândia (SP). 2016. 129 f. Tese (Doutorado em Geografia) - Instituto de Geociências e Ciências Exatas, Universidade Estadual Paulista, Rio Claro, 2016.

PINTON, L. de G.; CUNHA, C. M. L. da. O uso de geoindicadores em paisagem rural: subsídios à análise das mudanças morfológicas antropogênicas da Bacia do Córrego do Cavalheiro - Analândia (SP). Revista do Departamento de Geografia (USP), São Paulo, v. 29, p. 1-19, 2015.

RICCOMINI, C.; CRÓSTA, A. P. Análise preliminar de lineamentos em imagens de sensores remotos aplicada à prospecção mineral na área dos granitóides Mandira, SP. Boletim IG-USP, São Paulo, Série Científica, v.19, p. 2337, 1988 .

ROSS, J. L. S.; MOROZ, I. C. Mapa geomorfológico do estado de São Paulo: escala 1:500.000. São Paulo: FFLCH-USP; IPT; FAPESP, 1997. 2 v.

SAADI, A. Neotectônica da Plataforma Brasileira: esboço e interpretações preliminares. Geonomos, Belo Horizonte, v. 1, n. 1, p. 1-15, 1993.

SABINS Jr., F. F. Remote sensing: principles and interpretation. San Francisco: W. H. Freeman, 1978.426 p.

SILVA, C. L. da. Aspectos neotectônicos do médio Vale do Rio Moji-Guaçu: região de Piraçununga. 1997.169 f. Dissertação (Mestrado em Geologia Regional) - Instituto de Geociências e Ciências Exatas, Universidade Estadual Paulista, Rio Claro, 1997.

SOARES, P. C. et al. Análise morfoestrutural em fotos aéreas: aplicação na prospecção de hidrocarbonetos na Bacia do Paraná. In: Simpósio Brasileiro de Sensoriamento Remoto, 2., 1982, Brasília. Anais... Brasília: INPE, 1982. p. 157-168.

SOARES, P. C.; FIORI, A. P. Lógica e sistemática na análise e interpretação de fotografias aéreas em Geologia. Notícia Geomorfológica, Campinas, v. 16, n. 32, p. 71-104, dez. 1976.

TAYLOR, G. R. Image analysis techniques for the interpretation of air photo lineaments, petroleum exploration, Eromanga Basin, Australia. Geocarto International, v. 3, n. 3, p.53-60, 1988. 